FRI0123

BIOLOGICAL THERAPIES SURVIVAL IN RHEUMATOID ARTHRITIS PATIENTSIN CLINICAL PRACTICE: RESULTS FROM THE METEOR REGISTRY

Vicenç Torrente-Segarra ${ }^{1}$, Thomas Huizinga ${ }^{2}$, Karen Solomon-Escoto ${ }^{3}$, José Antonio P. Da Silva ${ }^{4}$, Douglas Veale ${ }^{5}$, Samar Al Emadi ${ }^{6}$, Sytske Anne Bergstra ${ }^{2}$. ${ }^{1}$ Hospital Comarcal Alt Penedès, Rheumatology, Vilafranca del Penedès, Spain; ${ }^{2}$ Leiden University Medical Center, Rheumatology, Leiden, Netherlands;

${ }^{3}$ University of Massachusetts Medical School-UMass Memorial Medical Center, Rheumatology, United States of America; ${ }^{4}$ Coimbra University Hospital, Rheumatology, Coimbra, Portugal; ${ }^{5}$ St. Vincent's University Hospital, Rheumatology, Dublin, Ireland; ${ }^{6}$ Hamad Medical Corporation, Senior Consultant Rheumatology-Head of Rheumatology Section, Qatar, Qatar

Background: Several biologic disease modifying anti-rheumatic drugs (bDMARDs) are currently available, but comparisons among these different drugs in clinical trials are rare and follow-up duration in trials is often limited. A comparison of these bDMARDs in daily practice can provide clinically relevant knowledge on treatment survival of all currently available bDMARDs.

Objectives: To assess the survival of each and every one of the biological therapies available in patients with rheumatoid arthritis (RA).

Methods: The METEOR registry is a multinational project that includes data on> 40,000 patients with RA from its diagnosis and prospectively, with proven reliability, in clinical practice. Inclusion criteria: patients> 18 years in biological treatment (bDMARD). Variables under study: disease onset date, bDMARD initiation and discontinuation date, bDMARD type (infliximab, certolizumab, adalimumab, golimumab, etanercept, rituximab, tocilizumab and abatacept), concomitant treatment, line of treatment. Clinical variables: TJC, SJC, ESR, CRP, BMI, patient's VAS, and RF and ACPA levels; smoking status. Cox regression analysis that was adjusted for several potential confounders.

Results: From the 47,263 patients registered in the total METEOR database, 11,132 were eligible for inclusion of the current study. Of these, 9,516 had sufficient data available and were included in the analyses. Included patients $(n=9,516)$ less often smoked than non-included patients $(n=1,616)$, but other baseline characteristics were very similar between groups (data not shonw).

Baseline features of all patients were similar.

Median time on bDMARD as 1 st line treatment for each drug is shown in Table 1, infliximab showed the longest median time on treatment. Using infliximab as 'reference' treatment, Table 2 shows abatacept, certolizumab, rituximab and tocilizumab showed higher hazard risk to finish the treatment prematurely, while adalimumab, golimumab or etanercept had similar results than infliximab.

Conclusion: after adjusting by several confounders, analysed data showed that most anti-TNF (infliximab, adalimumab, etanercept and golimumab) had a similar hazard to stop treatment in clinical practice. Other than anti-TNF bDMARD showed higher hazard to switch treatment than infliximab.

Disclosure of Interests: Vicenç Torrente-Segarra Speakers bureau: Roche, GSK, UCB, Thomas Huizinga Consultant for: Merck, UCB, Bristol Myers Squibb, Biotest AG, Pfizer, GSK, Novartis, Roche, Sanofi-Aventis, Abbott, Crescendo Bioscience Inc., Nycomed, Boeringher, Takeda, Zydus, Epirus, Eli Lilly, Karen Solomon-Escoto: None declared, José Antonio P. da Silva: None declared, Douglas Veale: None declared, Samar Al Emadi: None declared, Sytske Anne Bergstra Grant/research support from: Bristol-Myers Squibb provided funding for the completion of this study and the development of the abstract.

DOI: 10.1136/annrheumdis-2019-eular.1705

\section{FRI0124 FACTORS ASSOCIATED WITH PERSISTENT DRUG- FREE REMISSION IN PATIENTS WITH RHEUMATOID ARTHRITIS}

Larissa Valor, Melanie Hagen, Michaela Reiser, Arnd Kleyer, Fabian Hartmann, Bernhard Manger, Georg Schett, Jürgen Rech, Koray Tascilar, Retro: J Haschka, M Englbrecht, A Hueber, C Figueiredo, J Fogagnolo, HP Tony, S Finzel, S Kleinert, J Wendler, F Schuch, M Ronneberger, M Feuchtenberger, M Fleck, K Manger, W Ochs, M Schmitt-Haendle, HM Lorenz, H Nüsslein, R Alten, J Henes, K Krüger.

Friedrich-Alexander-University Erlangen-Nürnberg, Department of Internal Medicine 3, Rheumatology and Immunology, Erlangen, Germany

Background: Persistent drug-free remission of RA is a condition that is close to "cure" of the disease. However, long-term drug-free remission is considered to be rare and very challenging to reach. Also, little data are available that report how often persistent drug-free remission can be achieved and what kind of clinical characteristics are associated with such state.
Objectives: To evaluate factors associated with persistent drug-free remission in patients with rheumatoid arthritis

Methods: We analyzed the long-term observational follow-up phase of the randomized controlled RETRO (REduction of Therapy in RA Patients in Ongoing Remission) study on tapering and stopping of DMARDS in RA patients in stable remission (DAS28-ESR <2.6) (1,2). We included patients having completed the 1-year randomized controlled phase of RETRO, in which DMARD treatments were either continued, tapered or stopped. In the long-term extension, (i) patients who successfully stopped, continued DMARD stop, (ii) patients who relapsed in any of the 3 groups continued DMARD treatment, (iii) patients in the continuation arm remaining in remission underwent 50\% DMARD tapering followed by stopping after 6 months if still being in remission and (iv) patients in the tapering arm remaining in remission underwent DMARD stop. We assessed the percentage of patients in persistent drug-free remission in the overall population and the three randomization groups, the probability of persistent drug-free remission in the intervention groups compared to controls adjusted by baseline aCCP, erosive changes and use of biologic DMARDs in a logistic regression model and the baseline characteristics associated with reaching persistent drug-free remission.

Results: All 141 patients being in the long-term observational follow-up phase of the RETRO study for at least 1 year were analyzed. Among them DMARDs were initially continued (Control, $n=38$ ), tapered (Taper, $n=50$ ) or stopped (Taper/Stop $n=53$ ). 19/141 patients were lost to followup and the worst case scenario was assumed that all of them did not reach persistent drug-free remission. Median time after study entry (Q1Q3) was 69 (37-96) months as by December 2018. Overall number of patients in drug-free remission was $34 / 141(24.1 \%), 10 / 38(26 \%)$ in the control group, 6/50 (12\%) in the taper group and 18/53 (34\%) in the taper/stop group. After adjustment for baseline risk factors in the likelihood to reach persistent drug-free remission between the groups (OR:0.76, 95\%Cl: 0.29-1.99) was highly uncertain. Positive ACPA (OR: $3.38,1.01$ - 11.31) and erosive-state $(3.05,1.32$ - 7.06) at baseline were associated with a lower likelihood to reach persistent drug-free remission.

Conclusion: These data show that persistent drug-free remission can be reached in a subset of RA patients following a structured DMARD tapering approach after being in stable long-term DMARD control.

\section{REFERENCES:}

[1] Haschka J, et al. Relapse rates in patients with rheumatoid arthritis in stable remission tapering or stopping antirheumatic therapy: interim results from the prospective randomised controlled RETRO study. Ann Rheum Dis. 2016 Jan;75(1):45-51

[2] Rech J, et al. Prediction of disease relapses by multibiomarker disease activity and autoantibody status in patients with rheumatoid arthritis on tapering DMARD treatment. Ann Rheum Dis 2016;75:1637-44.

Disclosure of Interests: Larissa Valor: None declared, Melanie Hagen: None declared, Michaela Reiser: None declared, Arnd Kleyer Grant/ research support from: Lilly, Consultant for: Lilly, Speakers bureau: Abbvie, Fabian Hartmann: None declared, Bernhard Manger: None declared, Georg Schett: None declared, Jürgen Rech Grant/research support from: Bristol-Myers Squibb and Celgene (greater than $\$ 10,000$ ), Consultant for: Bristol-Myers Squibb, Celgene, Chugai, GlaxoSmithKline, Janssen, Eli Lilly, Novartis, Roche, Sanofi Aventis, and UCB (in total more than $\$ 10,000$ ), Speakers bureau: Bristol-Myers Squibb, Celgene, Chugai, GlaxoSmithKline, Janssen, Eli Lilly, Novartis, Roche, Sanofi Aventis, and UCB (in total more than $\$ 10,000)$, Koray Tascilar: None declared

DOI: 10.1136/annrheumdis-2019-eular.5677

\section{FRI0125 INDIVIDUAL PATIENT DATA META-ANALYSIS OF THE EFFECTIVENESS OF TOCILIZUMAB ON INHIBITING RADIOGRAPHIC PROGRESSION IN RHEUMATOID ARTHRITIS}

Maxime Verhoeven ${ }^{1}$, Janneke Tekstra ${ }^{1}$, Johannes W. G. Jacobs ${ }^{1}$, M Jacob. van Laar', Johannes Wj Bijlsma' ${ }^{1}$, Attila Pethoe-Schramm ${ }^{2}$, Michelle Borm ${ }^{3}$, Floris Lafeber ${ }^{1}$, Paco Welsing ${ }^{1}$. 'University Medical Center Utrecht, Utrecht, Netherlands; ${ }^{2}$ Hoffmann-La Roche, Basel, Switzerland; ${ }^{3}$ Roche Nederland BV, Woerden, Netherlands

Background: Several studies have shown that treatment with tocilizumab (TCZ) may reduce radiograph progression compared to treatment with methotrexate (MTX) in rheumatoid arthritis (RA). However, individual studies were not powered to detect differences in the incidence of progression. By combining several studies, a more precise estimate can be 